\title{
Research Article \\ The use of molecular markers (Ki67 \& p53) in premalignant and malignant cervical neoplasms
}

\author{
Mishra RK ${ }^{1}$, Vahikar $\mathrm{SU}^{2}$, Mitra $\mathrm{SK}^{3}$, Nagger $\mathrm{S}^{4}$, Shrivastava $\mathrm{K}^{5}$ \\ ${ }^{1}$ Dr. R.K. Mishra, Professor, ${ }^{2}$ Dr. Shilpa U. Vahikar, Associate Professor, ${ }^{3}$ Dr. Shaila Kumari Mitra, Associate Professor, \\ ${ }^{4}$ Dr. Seema Nagger, ${ }^{5}$ Dr. Kanchan Shrivastava, Assistant Professor. All authors affiliated with BRD Medical College, \\ Gorakhpur, UP, India.
}

Address for Correspondence: Dr. Shilpa U. Vahikar, Associate Professor, Department of Pathology, BRD Medical College, Gorakhpur, UP, India, Email Id: mall.shilpa@ yahoo.co.in

\begin{abstract}
Introduction: Cervical cancers are the second most frequent type of cancer in females. It develops from premalignant to invasive stages in a multistep process of carcinogenesis. The differentiation between cervical intraepithelial neoplasia III (CIN III) and early squamous cell carcinoma (SCC) of the cervix could be difficult to diagnose in certain situations unless we see the invasion. The objective of the study was to determine the expression of p53 \& Ki67 in CIN and cervical cancers and its correlation with grading and differentiation of cervical cancers with special emphasis on whether the use of Ki67 \& p53 markers could help in differentiating CIN III from early SCC. Material and Methods: A prospective study on 90 cases of cervical biopsies, including- cases of : chronic cervicitis (40), CIN III (19) and invasive carcinoma (31). All cases were evaluated by immunohistochemistry using Ki67 \& p53 monoclonal antibodies. Results: Both Ki67 \& p53 showed higher expression in CIN III and invasive cervical carcinoma than chronic cervicitis with statistically significant difference $\mathrm{p}<0.01$ and $\mathrm{p}<0.001$ respectively. High significant difference of p53 \& Ki67 expression was found between patients with CIN III and invasive cervical carcinomas. There was a clear trend for increasing number of cases with positive Ki67 \& p53 index with increasing grades of cervical cancer. Conclusion: Ki67 \& p53 showed increased expression from CIN III to SCC and it may be helpful adjunct in differentiating these two lesions. These markers could be used as biomarkers in the evaluation of the proliferative activity and progressive potential of dysplastic and neoplastic changes.
\end{abstract}

Key words: : Cervical cancers, Ki67 marker, p53 marker, CIN III, Cervical Carcinoma.

\section{Introduction}

Carcinoma of uterine cervix is the most frequent malignancy in women worldwide with an incidence of approximately 456.000 cases per year leading to 200.000 deaths per year [1].

Cervical cancer develops from premalignant to invasive stages in a multistep process of carcinogenesis. During this process many molecular structures are denovo expressed, while reference characteristic are lost. Identification of these molecular changes as tumour markers contributed to improve our capacity in diagnosis and evaluation of prognosis [2].

The epidemiological profile of the disease shows that it

Manuscript received: $25^{\text {th }}$ January 2016

Reviewed: $8^{\text {th }}$ February 2016

Author Corrected: $20^{\text {th }}$ February 2016

Accepted for Publication: $31^{\text {st }}$ March 2016 is related to sexual activity and $99 \%$ of cervical cancers are associated to Human papilloma virus (HPV) infection [3].

The risk of developing cancer depends on the HPV type. The high risk HPV types 16 and 18 are the most prevalent represent $59.8 \%$ and $15.0 \%$ respectively in case of invasive cancers [4].

However not all women who have HPV infection develop cervical cancer, suggesting that HPV alone is not sufficient for cervical carcinogenesis. Researchers are currently focused on other important cell cycle factors such as loss of growth suppression, increased cell growth rates and angiogenesis [5]. Thus, one major field of research was directed towards tumour proliferation and tumour invasion biomarkers as 


\section{Research Article}

potential negative prognostic factors [6]. Two of the cell cycle genes which may be involved include Ki67 and p53. Ki67, a proliferative marker known as predictive factor for tumour development, is defined as a nuclear antigen expressed during all active phases of the cell cycle $\left(\mathrm{G}, \mathrm{S}, \mathrm{G}_{2}\right.$ and $\mathrm{M}$ ) except $\mathrm{GO}$; the level of ki67 expression is used to determine the cell proliferation status [7]. In normal cervical squamous mucosa, Ki67 is detected essentially in parabasal layers, but also in certain basal layers [8].

Increased Ki67 reactive cells in the intermediate and superficial layers of the squamous epithelium correlate with the presence of cervical dysplasia, while the percentage and superficial location of positive cells in the cervical epithelium also correlates with the grade of cervical intra-epithelial neoplasia [9].

The p53 gene functions include cell cycle arrest and apoptosis in response to DNA damage. Normal p53 protein has a very short half life and thus the protein level is too low to be identified immunohistochemically. In contrast, mutant p53 proteins have a longer half life and can be easily detected by IHC methods [10]. The p53 gene is one of the most important targets of the HPV E6 gene. It was found that E6 protein of high risk HPV, but not of low risk HPV, could interact with p53 in vitro systems. In addition to the ability to stimulate p53 degradation, E6 protein inhibits several functions of wild type p53 and it competes with it for the most important p53 protein functions including suppression of malignant growth. It was also shown that E6 increased the level of mutagenesis and genomic instability [11].

As there is a strong requirement of prognostic biomarkers and classic factors for tumour aggressiveness which could be managed as predictive parameters in cancer cervix, we have conceived that current study aiming to deter mine the expression of p53 and Ki67 in CIN and cervical cancers and its correlation with grading and differentiation of cervical cancers.

\section{Material and Methods}

This is a prospective study on women submitted to cervical biopsies between Jan 2012 to Dec 2013, in the department of pathology, BRD Medical College, Gorakhpur. We evaluated the morphological changes in histological sections stained by Haematoxylin and Eosin $(\mathrm{H} \& \mathrm{E})$, according to the severity of cervical lesion (chronic cervicitis with CIN III and with invasive carcinoma of the cervix). The total number of cases was 90, comprising of 40 cases of chronic cervicitis, 19 cases of CIN III and 31 cases of invasive cervical carcinoma. Immunohistochemical stay was performed for p53 and Ki67 by using Biogenex monochlonal ntibodies by antigen-retrieval method. For all cases the same technical personnel performed the immunohistochemical staining. A positive control was used for every antibody, to eliminate the possibilities of wrong interpretation. Sections of chronic cervicitis were used as positive control.

Interpretation of Results: All slides were examined under light microscopy. Strong nuclear staining was regarded to denote p53 and Ki67 positivity. 100 cells were evaluated in representative high power fields to obtain the percentage of cell positivity. The degree of nuclear staining was graded depending on the percentage of cells stained. For p53 grade 0 samples with no positivity (negative), Grade-I when less than $10 \%$ of cells showing positivity (mild expression), Grade-II with $11 \%$ to $50 \%$ expression (moderate expression) and Grade-III with greater than $50 \%$ expression (intense expression) [12] For Ki67, Grade$1+, 2+$ and $3+$ was given when the Ki67 index was below 5\%, 5 to $30 \%$, and greater than $30 \%$ respectively [13]. The percentage of p53 and Ki67 protein staining for CIN III and SCC (Squamous cell carcinoma) were evaluated using the chi-square test. Any 'p' value $<0.05$ was considered to be statistically significant.

\section{Results}

Clinical Presentation: A total of 90 cases were taken for the present study, which included 40 (44.44\%) cases of chronic cervicitis, $19(21.11 \%)$ cases of CIN III and 31 (34.45\%) cases of invasive cervical carcinoma (keratinizing squmous cell carcinoma 9 (29.03\%) and non keratinizing squmous cell carcinoma $22(70.96 \%)$. The age of clinical presentation for all patients with cervical lesions including chronic cervicitis, CIN III and invasive cervical carcinoma ranged from 26 to 90 years with mean age of 51.11 years. Patients with cervical carcinoma (31-90, mean 56.22 years) were older than those with CIN (26-70, mean 44.57 years). According to the parity wise distribution maximum cases of CIN III (52.63\%) and of invasive cervical carcinoma (41.93\%) were in para 5-6. Predominant presenting feature in chronic cervicitis was pain in lower abdomen (37.5\%) while CIN III and carcinoma cervix it was bleeding per vaginum in $57.89 \%$ and $77.41 \%$ respectively. 


\section{Research Article}

P53 Expression: Positive staining for p53 expression was localized in the nuclei of dysplastic and carcinoma cells (Fig.1). 7 to 19 (36.84\%) premalignant (CIN III) cases were positive for p53. In contrast 21 of the $31(67.74 \%)$ malignant (SCC) cases were positive.

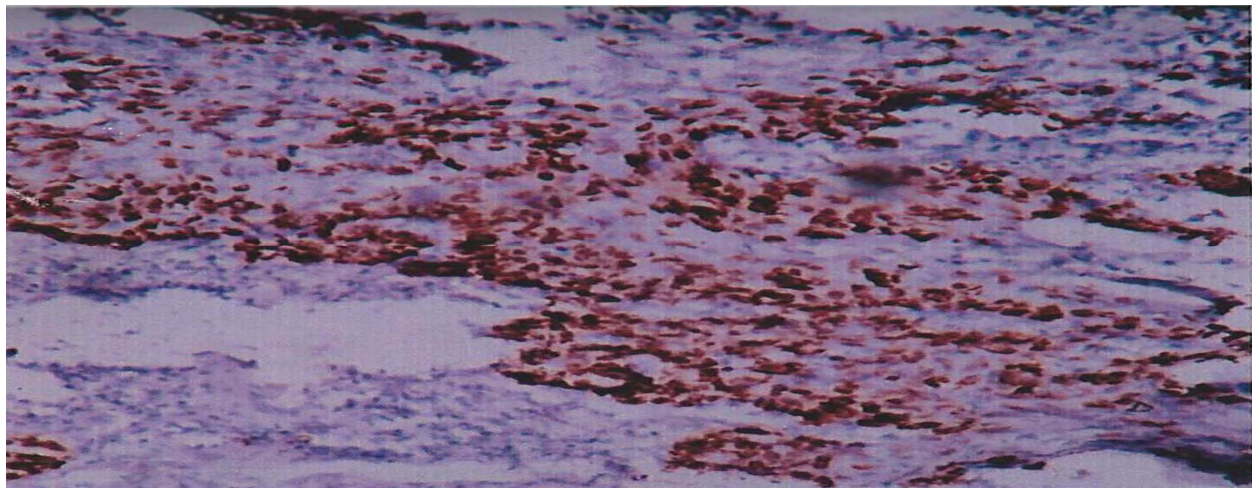

Figure 1: Photomicrograph showing P53 positivity in moderately differentiated Squamous Cell Carcinoma (X400)

The relationship between the percentage of cells with p53 expression i.e. its grading and histological diagnosis in summarized in Table-I. The difference of p53 protein expression between CIN III and SCC was statistically significant ('p' value <0.01), showed positive association between the invasion of cervical lesions and expression of p53.

Table I: Percentage of P53 Expression in CIN III and malignant Cervical Neoplasm.

\begin{tabular}{|c|c|c|c|c|}
\hline \multirow{2}{*}{$\begin{array}{c}\text { Histological } \\
\text { Diagnosis }\end{array}$} & \multicolumn{4}{|c|}{ \% of P53 Expression } \\
\cline { 2 - 5 } & Negative (0) & Grade 1 (1-10\%)) & Grade 2 (11-50\%) & Grade 3 (>50\%) \\
\hline CIN III (19) & $12(63.16)$ & $0(0)$ & $2(10.52)$ & $5(26.32)$ \\
\hline $\begin{array}{c}\text { Malignant } \\
\text { (SCC (31) }\end{array}$ & $10(32.26)$ & $0(0)$ & $0(0)$ & $21(67.74)$ \\
\hline
\end{tabular}

When the intensity of staining is evaluated Grade-III or intense expression of p53 protein was observed in 21/31 (67.74\%) of malignant cases, while only $5 / 19(26.32 \%)$ of CIN III cases were immunoreactive. The difference in the intensity of p53 protein immunoexpression was statistically significant ('p' value $<0.001$ on log linear analysis).

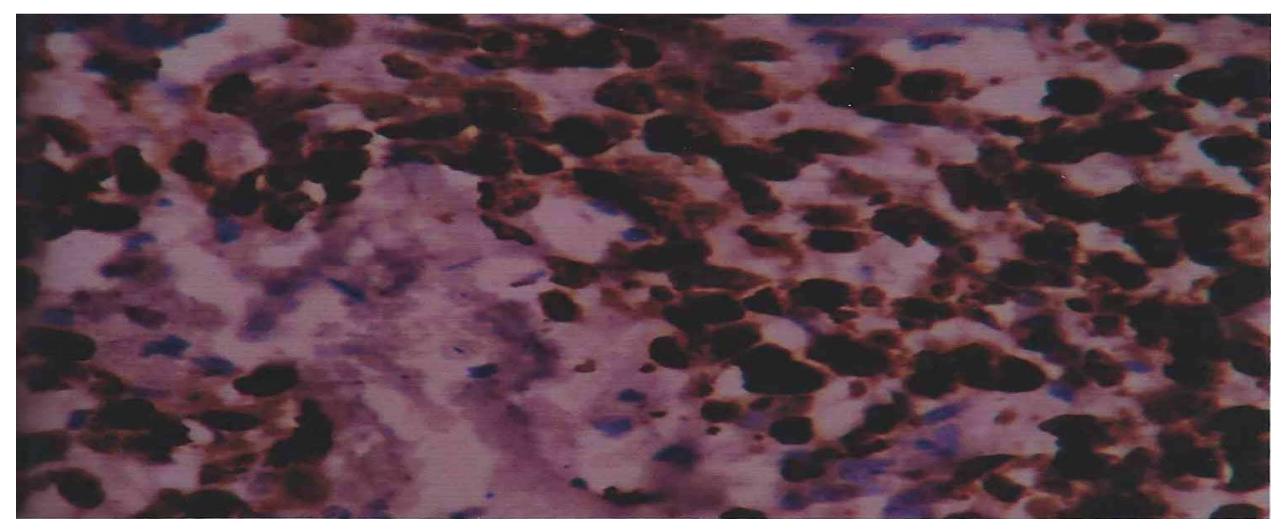

Figure 2- Photomicrograph showing Ki67 positivity in moderately differentiated Squamous Cell Carcinoma (X400)

Ki67 Expression: Positive staining for Ki67 was also localized in the nuclei of dysplastic and carcinoma cells (Fig.2). 6 (31.58\%) of 19 pre-malignant (CIN III) cases were positive for Ki67. In contrast 13/31 (41.94\%) malignant cases were positive. The relationship between the percentage of cells with Ki67 expression (i.e. grading) and their corresponding histological diagnosis is summarized in Table-II. 
Research Article

Table II: Percentage of Ki67 Expression in CIN III and malignant Cervical Neoplasm.

\begin{tabular}{|c|c|c|c|c|}
\hline \multirow{2}{*}{$\begin{array}{c}\text { Histological } \\
\text { Diagnosis }\end{array}$} & Negative & $\begin{array}{c}\text { Grade 1 (Low } \\
\text { Proliferation) }\end{array}$ & $\begin{array}{c}\text { Grade 2 (Moderate } \\
\text { Proliferation) }\end{array}$ & $\begin{array}{c}\text { Grade 3 (High } \\
\text { Proliferation) }\end{array}$ \\
\cline { 2 - 5 } & $13(68.42)$ & $0(0)$ & $5(26.32)$ & $1(5.26)$ \\
\hline CIN III (19) & $18(58.06)$ & $0(0)$ & $11(35.48)$ & $2(6.45)$ \\
\hline $\begin{array}{c}\text { Invasive } \\
\text { Cervical } \\
\text { Carcinoma (31) }\end{array}$ & & & & \\
\hline
\end{tabular}

The difference of Ki67 protein expression between CIN III and SCC was statistically significant $(\mathrm{p}<0.05)$ and showed positive association between the histological grades of cervical lesions and expression of Ki67.

When the intensity of staining is evaluated, Grade-II or moderate proliferation was observed in 5/19 (26.32\%) of CIN III cases, and 11/31 (35.48\%) of SCC cases while high proliferation is seen in $1(5.26 \%)$ of CIN III and $2(6.45 \%)$ of SCC cases. The difference in the intensity of Ki67 protein immunoexpression was statistically significant ('p' value $<0.001$ on $\log$ linear analysis).

Table III: Comparison between expression of Ki67and P53 with histological types SCC.

\begin{tabular}{|c|c|c|c|c|}
\hline \multirow{2}{*}{ I HC markers } & \multicolumn{2}{|c|}{ KSCC (9) } & \multicolumn{2}{c|}{ NKSCC (22) } \\
\cline { 2 - 5 } & Positive & Negative & Positive & Negative \\
\hline Ki67 & $4(44.45)$ & $5(55.55)$ & $9(40.90)$ & $13(59.10)$ \\
\hline P53 & $5(55.55)$ & $4(44.45)$ & $16(72.73)$ & $6(27.27)$ \\
\hline
\end{tabular}

All cases of chronic cervicitis were negative for p53 and Ki67. Ki67 expression showed higher expression in keratinizing squamous cell carcinoma than non-keratinizing SCC while p53 expression showed higher expression in non-keratinizing SCC than in keratinizing SCC, which is summarized in Table-III.

\section{Discussion}

Carcinogenesis is generally based on uncontrolled cell proliferation, assessed by Ki67 biomarker and abnormal apoptosis, cell growth and cell cycle, evaluated by p53 expression [7]. Recent advances in the immunopathogenesis of cancer, especially in cervical cancer, have been related to IHC evaluation of two important tumour biomarkers.

1. Ki67 Ag, a human nuclear protein expressed through the entire cycle except G0 phase, which is widely used to assess proliferation status [14].

2. p53 which is located on chromosome 17 P13.1 and it functions as cell cycle arrest and apoptosis in response to DNA damage. It is the most common target for genetic alteration in human tumours. This is one of the most important targets of the HPV E6 gene [12]. Because of the significant inter and intra-observer variability in interpreting invasive and non-invasive cervical biopsy specimens. There is a need to search for biomarkers to assist in diagnosis. Oncogenes and cell cycle regulators that may play a role in the genesis of cervical cancer include C-erb B2, p27, p53, p16INK4a and Ki67 [14].

Ki67 proliferation marker is already recognized and validated as specific and sensitive biomarker in cervical intraepithelial neoplasia. It is well demonstrated that Ki67 expression is increased in upper layers of cervical epithelia, being of major significance for the differentiation of non-neoplastic lesions that can mimic cancer [18].

As p53 protein concern, it's over expression is linked with control of cell growth, cell cycle and apoptosis. In uterine cervical carcinoma, the detection rate of p53 over expression by IHC has been reported to range from $8-74 \%$ and some reports have suggested that p53 over expression is important as a prognostic marker [15].

The current study was designed in order to investigate tumour proliferative activity (Ki67) and apoptosis in 
response to DNA damage (p53) as main determinants of cancer aggressiveness and biomarker distribution among histological cervical carcinoma types.

We were interested in demonstrating potential correlation concerning tumour biomarkers and aggressiveness of the tumour. Statistical analysis underwent has revealed certain statistical significant correlations, supporting either already known data from literature, either new information.

Thus, there have been demonstrated a significant relation between two biomarkers known to define tumour proliferation (Ki67) and apoptosis (p53), critical elements for cervical carcinoma aggressiveness.

Our study showed a higher incidence of cervical neoplasia in Indian community. When comparing the ratio of CIN III and squamous cell carcinoma in various ethnic groups, we found that Indians have higher incidence of squamous cell carcinoma compared to CIN. In contrast the ratio were reversed in Chinese community. A possible reason for this could be the lack of awareness, low socio-economy, in availability of resourses and that the Indians may have initially opted for traditional therapy and presented with an advance stage of disease [14].

The median age of women in our study was 56.22 years, ranging from 31-90 years. The maximum number of cases (CIN III and SCC) were in the age group of 4060 years which is consistent with data from other studies $[16,17]$.

This study revealed that ki67 expression correlates well with the invasive nature of squamous cell carcinoma, whereby the average percentage of malignant cell reactivity was $41.94 \%$ compared to CIN III which was $31.58 \%$. The average percentage of p53 expression was $36.84 \%$ in CIN III and $67.74 \%$ in invasive carcinoma.

Hence from above findings we observed that expression of Ki67 and p53 increases from premalignant to malignant lesions which was in accordance with other studies done by Kanupria Gupta [18], Geok Chin Tan [14] and Natalia Gaspar Munhoz [19]. This also suggests that p53 alteration is not an early event in the pathogenesis of cervical cancer.

We also observed that an increased Ki67 index and grading of p53 expression as the nature of the lesion progressed from dysplasia to squamous cell carcinoma.

\section{Research Article}

Intense expression of p53 was observed in all cases of invasive cervical carcinoma while it was seen in $26.32 \%$ of CIN III cases. Even the intensity of Ki67 staining was found to increase as the nature of the lesion changed from dysplasia to SCC. Similar findings were observed by Gupta K et $\mathrm{al}^{\mathbf{1 8}}$ and Natalia et al [19].

p53 expression was more in non-keratinising squamous cell carcinoma $(72.73 \%)$ than keratinizing squamous cell carcinoma $(55.55 \%)$.

Many reports have demonstrated the correlation between p53 gene mutation and unfavourable outcome in various human cancers, including lung, breast, bladder and cervical cancers [12].

Previous reports have shown that p53 over expression has a statistically significant correlation with poor outcome of cervical squamous cell carcinoma [20].

\section{Conclusion}

Hence, we conclude the increasing prevalence, Ki67 index and p53 expression with increasing grades of dysplasia and increase in progression from dysplasia to carcinoma shows that both of these could be used as biomarkers in the evaluation of the proliferative activity and progressive potential.

\section{Funding: Nil, Conflict of interest: Nil Permission from IRB: Yes}

\section{References}

1. Crum CP. The female genital tract. In: Kumar V, Fausto N, Abbas A. Robbins and contran pathologic basis of disease. $7^{\text {th }}$ edition. Elsevier W.B. Saunders press; 2005. 1098-1099p.

2. World Health Organisation (Feb 2006). Fact Sheet No. 297: 376-12.

3. Bauer HM, Hildesheim A, Schiffman MH, Glass AG, Rush BB, Scott DR, Cadell DM, Kurman RJ, Manos MM. Determinants of genital human papillomavirus infection in low-risk women in Portland, Oregon. Sex Transm Dis. 1993 Sep-Oct;20(5):274-8.

4. Psyrri A, DiMaio D. Human papillomavirus in cervical and head-and-neck cancer. Nat Clin Pract Oncol. 2008 Jan;5(1):24-31.

5. de Araujo Souza PS, Villa LL. Genetic susceptibility to infection with human papillomavirus and 


\section{Research Article}

development of cervical cancer in women in Brazil. Mutat Res. 2003 Nov;544(2-3):375-83.

6. Pandeli R, Cozma GL, Anton C, Neyara A. Tumour Angiogenesis as a predictor in Cervix carcinoma. J Prev Med. 2005; 13 (3-4): 72-77.

7. Panjkovic M, Ivkovic-Kapicl T. Ki67 expression in squamous intraepithelial lesions of the uterine cervix. Arch Oncol. 2006; 14 (1-2): 23-25.

8. Bulten J, van der Laak JA, Gemmink JH, Pahlplatz MM, de Wilde PC, Hanselaar AG. MIB1, a promising marker for the classification of cervical intraepithelial neoplasia. J Pathol. 1996 Mar;178(3):268-73.

9. Konish I, Fujii S, Nonogaki H, Nanbu Y, Iwai T, Mori T. Immunohistochemical analysis of estrogen receptors, progesterone receptors, Ki67 Antigen and HPV DNA in normal and neoplastic epithelia of uterine cervix. Cancer. 1991 sept 15; 68 (6) : 1340-50.

10. Finlay CA, Hinds PW, Tan TH, Eliyahu D, Oren M, Levine AJ. Activating mutations for transformation by p53 produce a gene product that forms an hsc70-p53 complex with an altered half-life. Mol Cell Biol. 1988 Feb;8(2):531-9.

11. Storey A, Thomas M, Kalita A, Harwood C, Gardiol D, Mantovani F, Breuer J, Leigh IM, Matlashewski G, Banks L. Role of a p53 polymorphism in the development of human papillomavirus-associated cancer. Nature. 1998 May 21;393(6682):229-34.

12. Tan GC, Sharifa NA, Salwati S, Shiran MS, Hatta AZ. $\mathrm{NaHo}_{2}$ Immunochemical study of p53 expression in premalignant and malignant cervical neoplasms. Med and Health 2007; 2 (2): 125-132.
13. Eun Ji Nam, Jae Wook Kim, Jong Wook Hong et al. J Gynecol Oncol. 2008 September: 1 (3).

14. Geok Chin Tan, Noor Akmal Sharifan, Mohd Sidik Shiran, shuib Salwati, Ahmad Zailani Hatta, Hock oon Paul-Ng. Ki67 and p53 for distinguishing CIN 3 and cervical squamous cell carcinoma. Asian Pacific Journal of Cancer Prevention. Vol 9, 2008; pg 781-783.

15. Huang LW, Chou YY, Chao SL, Chen TJ, Lee TT. p53 and p21 expression in precancerous lesions and carcinomas of the uterine cervix: overexpression of p53 predicts poor disease outcome. Gynecol Oncol. 2001 Nov;83(2):348-54.

16. ACOG Committee on Practice Bulletins-Gynecology. ACOG Practice Bulletin no. 109: Cervical cytology screening. Obstet Gynecol. 2009 Dec; 114(6): 1409-20.doi : 10.1097/ AOG. 0b013e 3181c6f8a4.

17. Jha AK, Jha J, Bista R, Basnet B, Kandel P, Lama G, Banthia P, Thakali K. A scenario of cervical carcinoma in a cancer hospital. JNMA J Nepal Med Assoc. 2009 Jul-Sep;48(175):199-202.

18. Kanupriya Gupta, Kiran Alam, Veen Maheshwari, Roobina Khan Jand, Rajyashri Sharma. Apoptotic Index and MIB 1 antibody expression in premalignant and malignant lesions of uterine cervix. Gynecol Obs. 2013: 173. Doi 10; 4172/2161-0932.1000173.

19. Natalia Gaspar Munhoz, Damaris Aparecida Rodrigues, Juliang Ligveireds Pedregosa, Juliana Olsen Rodrigues et al. The open pathology Journal. 2009; 3 : 10-17

20. Oka K, Suzuki Y, Nakano T. p27 and p53 expression in cervical squamous cell carcinoma patients treated with radiation therapy alone. Radiotherapeutic effect and prognosis. Cancer. 88; 2766-2773.

\section{How to cite this article?}

Mishra RK, Vahikar SU, Mitra SK, Nagger S, Shrivastava K.The use of molecular markers (Ki67 \& p53) in premalignant and malignant cervical neoplasms. Trop J Path Micro 2016;2(1):3-8.doi: 10.17511/jopm.2016.i01.02 